\title{
An Observational Study of Circulating Plasma and Serum Insulin-Like Growth Factor 1 as Prognostic Biomarkers in Surgical Hepatocellular Carcinoma Patients
}

\author{
Ahmed Kaseb ${ }^{1, *}, \#$, Simona Dima ${ }^{2, \#}$, Roberto Carmagnani Pestana ${ }^{1}$, Marek Ancukiewicz $^{3}$, Dana Cucu ${ }^{4}$, \\ Andrei Sorop ${ }^{2}$, Raluca Florea ${ }^{2}$, Nicolae Bacalbasa ${ }^{2}$, Dana Tomescu ${ }^{2}$, Vlad Herlea², Cristiana Tanase ${ }^{2}$, \\ Irinel Popescu, ${ }^{2, *}$, Dan G. Duda ${ }^{5, *}$
}

'Department of Gastrointestinal Medical Oncology,

The University of Texas MD Anderson Cancer Center, Houston, TX, USA

${ }^{2}$ Center for Digestive Disease and Liver Transplantation, Fundeni Clinical Institute,

Bucharest, Romania

${ }^{3}$ Probabilitas LLC, Acton, MA, USA

${ }^{4}$ Department of Anatomy, Physiology, and Biophysics, Faculty of Biology,

University of Bucharest, Bucharest, Romania

${ }^{5}$ Department of Radiation Oncology, Massachusetts General Hospital and Harvard Medical

School, Boston, MA, USA.

\section{ABSTRACT}

Identification of biomarkers that correlate with prognosis is crucial in hepatocellular carcinoma (HCC) because of the high recurrence rates seen after surgical treatments. Serum levels of $\alpha$-fetoprotein (AFP) are widely used clinically, but the prognostic value of AFP remains unclear. AFP levels are influenced not only by the presence of HCC but also by the severity of the underlying liver disease. Furthermore, AFP could be normal in up to $30 \%$ of HCC patients. Thus, additional biomarkers are needed. Insulin-like growth factors 1 (IGF-1) is a growth factor with dose-dependent proliferation and anabolic effects, and its interaction with IGF-1 receptor (IGF-1R) may promote tumor progression. On the other hand, hepatic synthesis of IGF-1 is significantly reduced due to underlying chronic liver disease in HCC patients, and previous studies demonstrated that circulating IGF-1 is a useful predictor of hepatic reserve in HCC patients. We evaluated circulating IGF-1 and AFP levels in a cohort of HCC patients undergoing liver resection or liver transplantation at a single institution (Fundeni Clinical Institute, Romania). We found that plasma IGF-1 was decreased in HCC patients as compared with healthy individuals, and that plasma IGF-1 was associated with the presence of cirrhosis in HCC patients. In addition, we found that plasma IGF-1 levels were significantly associated with disease-free survival (DFS) and overall survival (OS). This correlation was due to the significant association between higher IGF-1 and more favorable DFS and OS following liver transplantation. Independent validation of this biomarker is warranted in the setting of liver transplantation to confirm and further define the prognostic implications of plasma IGF-1 in HCC patients.

\section{INTRODUCTION}

Despite recent progress in local and systemic therapy of hepatocellular

\author{
*Corresponding authors: \\ Ahmed O. Kaseb, MD \\ E-mail: akaseb@mdanderson.org \\ Irinel Popescu, MD, PhD \\ E-mail: irinel.popescu220@gmail.com \\ Dan G. Duda, DMD, PhD \\ E-mail: gduda@partners.org.
}

\#These authors contributed equally.

Received: 02.04.2019

Accepted: 20.04.2019

Copyright (1) Celsius Publishing House www.sgo-iasgo.com 
carcinoma $(\mathrm{HCC})$, this frequent malignancy remains a global health challenge. The International Agency for Research on Cancer estimated that 745,500 liver cancer-related deaths occurred worldwide in 2012 (1). $\mathrm{HCC}$ most commonly arises in the setting of underlying liver disease, secondary to either viral hepatitis, particularly caused by hepatitis B (HBV) or hepatitis C (HCV) virus, or other non-viral chronic liver diseases, such as alcoholic and non-alcoholic steatohepatitis $(2,3)$. As a result of inefficient screening and its asymptomatic nature in the early stages, the majority of HCC cases are detected in advanced stages $(4,5)$. There is a significant unmet need for new effective therapies for this aggressive malignancy, and prognosis remains poor (6). Five-year recurrence rates approach $70 \%$ following surgical resection, and $10 \%$ to $54 \%$ of patients may have tumor recurrence after liver transplantation (6-10). In this context, identification of biomarkers that correlate with earlier detection and prognosis is crucial and can be valuable in defining the patients most likely to benefit from a particular treatment. Serum level of $\alpha$-fetoprotein (AFP) is widely used clinically, but its prognostic value remains unclear. AFP could be normal in up to $30 \%$ of HCC cases and its levels are influenced not only by the presence of HCC, but also by the severity of the underlying liver disease (11). Thus, AFP is a biomarker with poor sensitivity and specificity (12), and additional biomarkers are needed.

The GH-IGF system is an endocrine system consisting of growth hormone $(\mathrm{GH})$, insulin-like growth factors 1 and 2 (IGF-1 and IGF-2) and associated carrier proteins, and somatostatin (SST) (13). The GH-IGF system regulates cell proliferation, differentiation, and metabolism, and contributes to the pathogenesis of various malignancies, including HCC (14-16). IGF-1 is a growth factor with dose-dependent proliferation and anabolic effects $(17,18)$. Binding of IGF-1 to the IGF-1 kinase receptor (IGF-1R) leads to downstream activation of PI3K/AKT and MAPK pathways $(14,19)$. In this manner, IGF-1/IGF-1R axis may promote tumor progression or treatment resistance (20). Indeed, IGF-1R expression is upregulated in HCC, and IGF-1 inhibition can reduce the growth and invasion of HCC cells in vitro $(21,22)$. Moreover, published data also suggest that IGF signaling could contribute to resistance to sorafenib, and antiVEGFR tyrosine kinase inhibitor approved for advanced HCC $(23,24)$. Consistent with this hypothesis, we previously reported that an increase in plasma IGF-1 after treatment with the anti-VEGFR tyrosine kinase inhibitor cediranib was associated with shorter progression-free survival (PFS) in advanced HCC patients (25).

On the other hand, circulating levels of IGF-1 decrease sharply in patients with chronic liver diseases and $\operatorname{HCC}(15,26-33)$ because the liver synthesizes most of the circulating IGF-1 and previous studies demonstrated that serum IGF-1 is a useful predictor of hepatic reserve in HCC patients $(14,15,31)$. For example, lower baseline serum IGF-1 levels were associated with shorter overall survival (OS) in patients with HCC after surgical resection and were proposed as a prognostic factor for early recurrence (34). Similarly, lower pretreatment serum IGF-1 was associated with higher risk of relapse following TACE in HCC patients $(34,35)$.

Given this dual biological and prognostic role of IGF-1 pathway in underlying chronic liver disease and in HCC progression, respectively, we evaluated plasma and serum IGF-1 in an observational study of HCC patients, with or without cirrhosis, who underwent surgical treatments at a single institution. We examined the biomarker value of circulating IGF-1 in identifying patients with cirrhosis, and its association with survival outcomes in HCC patients treated with surgical resection or liver transplantation.

\section{PATIENTS AND METHODS}

\section{Patients and treatments}

Study enrolled patients who were diagnosed with $\mathrm{HCC}$ and underwent surgical treatments at Fundeni Clinical Institute, Bucharest, Romania. Treatment selection (resection versus transplantation) was based on the tumor stage, the liver function evaluation using the BCLC scoring system, availability of liver donor, and surgeon's decision. Inclusion criteria allowed for prior locoregional treatments such as TACE. Exclusion criteria included distant metastasis and other primary liver cancers. We evaluated hepatitis viral markers B, C and $D$ (HBV, HCV and HDV) and liver function parameters. Tumor recurrence was diagnosed according to the EASL-criteria. Patients were examined for HCC recurrence by ultrasonography. If recurrence was suspected, lesions were confirmed by contrast-enhanced MRI and lung $\mathrm{CT}$. After recurrence, depending on the extent and localization of HCC recurrence, patients were assessed and received surgical or interventional (TACE or radiofrequency ablation) treatment. Patients with recurrence who were not eligible for surgical or interventional therapy were offered systemic therapy including sorafenib or radiotherapy. The study observed all the ethical guidelines of the 1975 Declaration of Helsinki and was approved by the Fundeni Clinical Institute Review board (30884/22.10.2014). No organs from executed prisoners were used. All study 
participants provided written informed consent prior to enrollment in this study.

\section{Measurement of plasma and serum biomarkers}

Plasma and serum aliquots were prepared from blood samples obtained prior to surgery and were stored at $\leq 78^{\circ} \mathrm{C}$ until collection of all samples. These samples were used to measure circulating concentrations of IGF-1 and AFP. Serum AFP was measured as per standard of care. Plasma AFP was measured using human AFP ELISA Kit (Catalog \# : KA0202, Abnova, Walnut, CA). IGF-1 was measured using ELISA kits (R\&D Systems, Minneapolis, MN). All samples were measured in duplicate in the CLIA-certified core of the Steele Laboratories at Massachusetts General Hospital, Boston, USA.

\section{Statistical analysis}

Time-to-recurrence was calculated as the period of time (in months) the from the initial surgical treatment to the first tumor recurrence. Freedom of liver recurrence (FLR) was defined as the time to local tumor recurrence, disease-free survival (DFS) as the time to any tumor recurrence (local or distant-organ metastasis). OS was calculated as the period of time from the time of HCC resection until date of death or last follow-up. Circulating IGF-1 and AFP correlations with FLR, DFS and OS were tested using Wald test in univariate Cox regression analysis, using log- transformed covariates, and stratifying by treatment type. Comparison of biomarker levels was performed using exact Wilcoxon test.

\section{RESULTS}

\section{Patient characteristics}

The study enrolled $153 \mathrm{HCC}$ patients. Of these, 84 patients had valid measurements of IGF-1 in plasma prior to surgery for liver resection $(n=31)$ or liver transplantation $(n=53)$, and 69 patients had serum collected prior to surgery for liver resection. As expected, there were significant differences between the groups in patient characteristics. Patients undergoing liver transplantation were younger (57 vs $63 \mathrm{yr}$ ), had smaller tumors ( 3.8 vs $5.3 \mathrm{~cm}$ ), higher international normalized ratio (INR) (1.4 vs 1.0), more frequently viral etiology and cirrhosis ( $100 \%$ vs $80 \%$ ) than HCC patients in the liver resection group (table 1). Moreover, approximately half of the patients undergoing liver transplantation received a prior treatment (TACE) while all except 1 patient were treatment-naïve in the liver resection group.

\section{Pretreatment plasma and serum biomarkers levels in HCC patients stratified by surgical intervention}

We measured plasma and serum levels of IGF-1 and AFP in HCC patients and healthy individuals, as a control. We found comparable values in plasma IGF-1

Table 1 - Patient characteristics and surgical treatments $(n=84)$

\begin{tabular}{|c|c|c|c|}
\hline Variable & Level & Value & \\
\hline Age & Median (Range) - in yr & $59(53-63)$ & \\
\hline Underlying Liver Disease & $\begin{array}{l}\text { HBV - \% (N) } \\
\text { HCV }-\%(N) \\
\text { HDV }-\%(N)\end{array}$ & $\begin{array}{l}54.8 \%(46 / 84) \\
36.9 \%(31 / 84) \\
32.1(27 / 84)\end{array}$ & \\
\hline Surgical Treatment & $\begin{array}{l}\text { Liver Resection - \% (N) } \\
\text { Liver Transplantation - \% (N) } \\
\text { Synchronous - \% (N) }\end{array}$ & $\begin{array}{l}63.1 \%(53 / 84) \\
36.9 \%(31 / 84) \\
1.2 \%(1 / 84)\end{array}$ & \\
\hline Number of Nodular Tumors & $\begin{array}{l}1-\%(N) \\
2-\%(N) \\
3-\%(N) \\
4-\%(N) \\
8-\%(N)\end{array}$ & $\begin{array}{l}69.1 \%(56 / 81) \\
18.5 \%(15 / 81) \\
9.9 \%(8 / 81) \\
1.2 \%(1 / 81) \\
1.2 \%(1 / 81)\end{array}$ & \\
\hline Longest Tumor Dimension & Median (Range) - in cm & $4.4 \pm 2.2(76)$ & \\
\hline INR & Median (Range) - in sec & $1.2[1.0,1.4]$ & \\
\hline Pre-operative cirrhosis & $\begin{array}{l}\text { Present - \% (N) } \\
\text { Absent - \% (N) }\end{array}$ & $\begin{array}{l}92.9 \%(78 / 84) \\
7.1 \%(6 / 84)\end{array}$ & \\
\hline Plasma IGF-1 & Median and interquartile range in $\mathrm{pg} / \mathrm{ml}$ & $\begin{array}{l}\text { No liver cirrhosis } \\
46.9[40.4,67.3](8)\end{array}$ & $\begin{array}{l}\text { Liver cirrhosis } \\
27.2[18.6,42.1](78)\end{array}$ \\
\hline
\end{tabular}


between HCC patients who underwent resection versus transplantation (table 2). However, these concentrations were significantly lower in both HCC groups compared to healthy individuals (table 2). Moreover, serum values of IGF but not AFP were significantly higher than the concentrations measured in plasma (table 2). Finally, plasma AFP was not significantly different between HCC patients who underwent resection versus transplantation (table 2). These data suggest that circulating IGF-1 levels are decreased in HCC patients compared to control due to underlying liver damage, and that IGF-1 plasma and serum levels might be different.

\section{Circulating biomarker levels stratified by presence of cirrhosis}

Thus, we next stratified the groups by absence versus presence of cirrhosis. This analysis showed that plasma IGF-1 was significantly lower in cirrhotic $(27.2 \mathrm{pg} / \mathrm{ml}[18.6,42.1])$ versus non-cirrhotic $(46.9 \mathrm{pg} / \mathrm{ml}$ $[40.4,67.3])$ HCC patients $(p=0.0071)$. A significant difference was also seen when plasma IGF-1 was analyzed only in the resected group: biomarker levels were lower $(23.8 \mathrm{pg} / \mathrm{ml}[18.3,41.3], \mathrm{n}=25)$ in cirrhotic versus non-cirrhotic $(46.1 \mathrm{pg} / \mathrm{ml} \quad[35.7,55.8], \mathrm{n}=7) \quad \mathrm{HCC}$ patients $(p=0.020)$.

\section{Association between pretreatment plasma and serum biomarkers levels in HCC patients and survival outcomes after surgical interventions}

Next, we evaluated the prognostic biomarker value for plasma and serum IGF-1 and AFP by testing their correlation with FLR, DFS and OS in HCC patients undergoing surgical treatments. In the overall cohort, OS and DFS were both inversely associated with plasma IGF-1 level [hazard ratio $(H R=0.81$ and $H R=0.79$, respectively, both $p<0.05$ ) (table 3). The HR for FLR was 0.79 but did not reach statistical significance $(p=0.25)$ (table 3). When stratified by surgical treatment type, all three outcome measures were all significantly associated with plasma IGF-1 in the liver transplant group ( $H R=0.81$ for OS, $H R=0.78$ for DFS and $H R=0.67$ for $F L R$, all $p<0.05$ ) (table 3). Interestingly, there was no association between plasma IGF-1 and any of the outcomes measured in the liver resection group (table 3). None of the outcome measures associated with plasma AFP, in the overall population or after stratification by treatment (table 3). Moreover, neither serum IGF-1 nor serum AFP showed any association with DFS (HR $=0.98$, $p=0.84$ and $H R=0.98, p=0.95$, respectively) or OS ( $H R=0.96, p=0.63$ and $H R=1.00, p=0.97$, respectively) after surgery for $\mathrm{HCC}$ resection $(n=68)$.

\section{DISCUSSION}

IGF-1 plays an important role in the pathogenesis of chronic liver disease and progression to HCC, as demonstrated by both in vitro experiments and in vivo xenograft data. Epidemiologic and clinicopathological studies further support an association of the GH-IGF system with the development of HCC. In this study in a Romanian population, plasma IGF-1 was decreased in HCC patients as compared with healthy individuals, and plasma IGF-1 was associated with the presence of cirrhosis in HCC patients. Our results are consistent with previous findings of reduced IGF-1 levels in cirrhosis (36-40). Reduced levels of IGF-1 in patients with hepatic cirrhosis are attributed to liver damage, as hepatocytes are the primary source of IGF-1 in response to $\mathrm{GH}$ stimulation $(35,41)$. The observation that IGF-1 synthesis reflects the severity of liver fibrosis in chronic hepatitis C supports this hypothesis (35). Further, in agreement with our findings, previous

Table 2 - Plasma and serum IGF-1 and AFP in HCC patients and healthy individuals

\begin{tabular}{|c|c|c|c|c|}
\hline Biomarker & Liver Resection & Liver Transplantation & Control (healthy) & Comments \\
\hline Plasma IGF-1 (pg/ml) & $\begin{array}{c}30.7[20.2,45.3] \\
(n=32)\end{array}$ & $\begin{array}{c}27.4[19.1,44.2] \\
(n=54)\end{array}$ & $\begin{array}{c}71.0[62.0,79.0] \\
(n=12)\end{array}$ & $\begin{array}{l}\text { No difference } \\
\text { between resection } \\
\text { vs transplant cohorts }(p=0.58) \\
\text { Lower in both surgical cohorts } \\
\text { vs control }(p<0.0001)\end{array}$ \\
\hline Serum IGF-1 (pg/ml) & $52[35,70](\mathrm{n}=69)$ & $\mathrm{N} / \mathrm{A}$ & $\mathrm{N} / \mathrm{A}$ & $\begin{array}{l}\text { Higher level in serum vs plasma for } \\
\text { IGF-1 }(p=0.0004)\end{array}$ \\
\hline Plasma AFP (pg/ml) & $12.5[5.6,20.0](n=32)$ & $7.0[3.3,19.9](n=54)$ & $\mathrm{N} / \mathrm{A}$ & $\begin{array}{l}\text { No difference between resection vs } \\
\text { transplant cohorts }(p=0.18)\end{array}$ \\
\hline Serum AFP $(\mathrm{pg} / \mathrm{ml})$ & $13.5[3.7,20.0](n=69)$ & $\mathrm{N} / \mathrm{A}$ & $\mathrm{N} / \mathrm{A}$ & $\begin{array}{l}\text { No difference in level in serum vs } \\
\text { plasma for AFP }(p=0.77)\end{array}$ \\
\hline
\end{tabular}


Table 3 - Correlation between background clinical variables and freedom of liver recurrence (FLR), disease-free survival (DFS) and overall survival (OS) in HCC patients undergoing surgical treatments. P-value from Wald test in a univariable Cox regression using log-transformed covariates

\begin{tabular}{|c|c|c|c|c|c|c|}
\hline \multirow[t]{2}{*}{ Biomarkers/ Outcome } & \multicolumn{2}{|c|}{ FLR } & \multicolumn{2}{|c|}{ DFS } & \multicolumn{2}{|c|}{ OS } \\
\hline & $\mathrm{HR}[95 \% \mathrm{Cl}](\mathrm{n})$ & P-value & $\mathrm{HR}[95 \% \mathrm{Cl}](\mathrm{n})$ & P-value & $\mathrm{HR}[95 \% \mathrm{Cl}](\mathrm{n})$ & P-value \\
\hline \multicolumn{7}{|c|}{ All patients } \\
\hline IGF-1 & $0.79[0.53,1.18](84)$ & 0.25 & $0.79[0.66,0.96](84)$ & 0.016 & $0.81[0.68,0.95](83)$ & 0.011 \\
\hline AFP & $1.04[0.69,1.56](84)$ & 0.85 & $0.96[0.75,1.24](84)$ & 0.77 & $1.02[0.77,1.36](83)$ & 0.88 \\
\hline \multicolumn{7}{|c|}{ LT cohort } \\
\hline IGF-1 & $0.67[0.48,0.93](53)$ & 0.010 & $0.78[0.64,0.93](53)$ & 0.0075 & $0.81[0.68,0.97](52)$ & 0.019 \\
\hline AFP & $0.89[0.48,1.65](53)$ & 0.71 & $0.89[0.63,1.25](53)$ & 0.50 & $0.93[0.65,1.33](52)$ & 0.69 \\
\hline \multicolumn{7}{|c|}{ LR cohort } \\
\hline IGF-1 & $2.12[0.85,5.25](31)$ & 0.11 & $1.07[0.53,2.16](31)$ & 0.86 & $0.66[0.28,1.58](31)$ & 0.35 \\
\hline AFP & $1.17[0.67,2.05](31)$ & 0.59 & $1.06[0.72,1.58](31)$ & 0.76 & $1.22[0.72,2.08](31)$ & 0.46 \\
\hline
\end{tabular}

studies have reported significant reduction of serum IGF-1 levels in patients with HCC as compared to cirrhosis and healthy controls (39, 42-44).

Our results demonstrate, additionally, that plasma IGF-1 levels were significantly associated with DFS and $\mathrm{OS}$ in surgical HCC patients. However, this correlation was due to the significant associations seen between higher IGF-1 with FLR, DFS and OS following liver transplant in HCC patients. Patients with higher baseline IGF-1, had 33\% lower chance of liver recurrence and $29 \%$ lower rate of death following transplantation. The recurrence of HCC after liver transplant was associated with a poor prognosis, and identification of high-risk groups may allow tailoring of immunosuppression regimens, selection of patients for closer surveillance, or appropriate enrolment in trials of adjuvant therapy, such as sorafenib (45-49). To the best of our knowledge, we provide the first description of preoperative IGF-1 levels correlation with outcomes following liver transplant in an HCC population. These findings support incorporating preoperative IGF-1 into prognostic biomarkers work up before liver transplant similar to serum AFP which has emerged as an important predictor of tumor recurrence following surgery or liver transplant (50-52). Previous studies had explored the role of IGF-1 as a marker of liver function after liver transplantation $(53,54)$. Salso et al. reported that IGF-1 levels persistently lower than $90 \mathrm{mUI} / \mathrm{mL}$ later than one week following liver transplant were associated with significantly worse outcomes - short-term survival was observed in less than $13 \%$ of these patients (54) given that circulating IGF-1 reflects poor liver reserve status.

In our study, baseline (plasma or serum) IGF-1 levels were not associated with outcomes following surgical resection. This is in contrast to previous studies demonstrating that low preoperative circulating IGF-1 is significantly associated with risk of early recurrence in HCC patients $(34,55)$. Shen et al. evaluated HCC patients submitted to surgical resection and demonstrated that, in multivariate models, comparing the first with the fourth quartile of circulating serum IGF-1, lower levels were associated with a $216 \%$ increased risk of $\mathrm{HCC}$ recurrence [HR=3.16 (95\% Cl: 1.79-4.28)](55).

In our study, serum IGF-1 levels were significantly higher than plasma IGF-1 levels. This is consistent with a 2015 study that evaluated circulating IGF-1 levels in 30 healthy female participants in the PLCO trial, which demonstrated that median serum IGF-1 was 101.8 $\mathrm{ng} / \mathrm{mL}$ versus $90.6 \mathrm{ng} / \mathrm{mL}$ in the plasma $(p<.0001)(56$, 57). That study suggested that serum and plasma IGF-1 levels are significantly correlated $(49,57)$. However, these results highlight the caution required comparing biomarkers in populations with different specimen types (plasma versus serum) and different patient populations.

Finally, our findings indicate that baseline AFP levels were also not associated with survival outcomes. Previous studies have demonstrated AFP levels to be significantly associated with outcomes following surgical resection and liver transplantation in HCC patients (50-52). Ma et al. showed that patients with preoperative serum AFP $\leq 20 \mathrm{ng} / \mathrm{mL}$ had lower postoperative 2-year recurrence rate, and higher 18-month survival rate and 24-month survival rate $(p<0.05)(51)$. Berry et al. demonstrated that baseline AFP independently predicts survival following liver transplantation for $\mathrm{HCC}$ - patients within the Milan criteria who presented with elevated AFP had substantially higher risk of death (for a serum AFP level $\geq 66 \mathrm{ng} / \mathrm{mL}$, $\mathrm{HR}=1.93,95 \% \mathrm{Cl}=1.74-2.15)$ (58). The reasons for these inconsistent findings are also unknown and may depend on differences between methodologies or 
patient populations. There are several limitations in this study. First, we conducted a single-center study with a relatively small sample size. Second, this was an observational study, and therefore causality cannot be inferred. Third, we had no serum IGF-1 measurements from patients undergoing liver transplantation, which could explain some of the observations that are inconsistent with the published literature on serum IGF-1. Lastly, we did not evaluate other circulating factors related to the GH-IGF axis, including IGF-2 and IGF binding protein 3 (IGFBP-3), which is the main IGF-1 binding protein. Nevertheless, our study represents the first study of plasma IGF-1 as a candidate biomarker of outcome in an HCC transplant population. Clearly, this hypothesis generating finding need to be validated in larger studies.

In summary, we demonstrate that decreased plasma IGF-1 levels correlate with the presence of cirrhosis in HCC patients, and that elevated plasma IGF-1 could be explored as a promising non-invasive biomarker of good prognosis in HCC patients treated with liver transplantation. Independent validation of this biomarker is warranted in the setting of liver transplantation to confirm and further define the prognostic implications of plasma IGF-1 in this population.

\section{REFERENCES}

1. Torre LA, Bray F, Siegel RL, Ferlay J, Lortet-Tieulent J, Jemal A. Global cancer statistics, 2012. CA Cancer J Clin. 2015; 65(2):87-108.

2. Singal AG, El-Serag HB. Hepatocellular Carcinoma From Epidemiology to Prevention: Translating Knowledge into Practice. Clin Gastroenterol Hepatol. 2015;13(12):2140-51.

3. Daher S, Massarwa M, Benson AA, Khoury T. Current and Future Treatment of Hepatocellular Carcinoma: An Updated Comprehensive Review. J Clin Transl Hepatol. 2018 Mar 28;6(1):69-78.

4. Singal AG, Nehra M, Adams-Huet B, Yopp AC, Tiro JA, Marrero JA, et al. Detection of hepatocellular carcinoma at advanced stages among patients in the HALT-C trial: where did surveillance fail? Am J Gastroenterol. 2013 Mar;108(3):425-32.

5. El-Serag HB, Lenhard Rudolph K. Hepatocellular Carcinoma: Epidemiology and Molecular Carcinogenesis. Gastroenterology. 2007;132(7):2557-76.

6. Tannus RK, Almeida-Carvalho SR, Loureiro-Matos CA, MiziaraGonzalez A, Salzedas-Netto AA, Szejnfeld D, et al. Evaluation of survival of patients with hepatocellular carcinoma: A comparative analysis of prognostic systems. PLoS One. 2018;13(4):e0194922.

7. Nissen NN, Menon V, Bresee C, Tran TT, Annamalai A, Poordad F, et al. Recurrent hepatocellular carcinoma after liver transplant: identifying the high-risk patient. HPB . 2011;13(9):626-32.

8. Mazzaferro V, Sposito C, Zhou J, Pinna AD, De Carlis L, Fan J, et al. Metroticket 2.0 Model for Analysis of Competing Risks of Death After Liver Transplantation for Hepatocellular Carcinoma. Gastroenterology. 2018:154(1):128-39.

9. Pecchi A, Besutti G, De Santis M, Del Giovane C, Nosseir S, Tarantino G, et al. Post-transplantation hepatocellular carcinoma recurrence: Patterns and relation between vascularity and differentiation degree. World J Hepatol. 2015;7(2):276-84.

10. Lerut J, lesari S, Foguenne M, Lai Q. Hepatocellular cancer and recurrence after liver transplantation: what about the impact of immunosuppression? Transl Gastroenterol Hepatol. 2017;2:80.

11. El-Serag HB, Kanwal F, Davila JA, Kramer J, Richardson P. A new laboratory-based algorithm to predict development of hepatocellular carcinoma in patients with hepatitis $\mathrm{C}$ and cirrhosis. Gastroenterology. 2014;146(5):1249-55.e1.

12. Sanai FM, Sobki S, Bzeizi KI, Shaikh SA, Alswat K, Al-Hamoudi W, et al. Assessment of Alpha-Fetoprotein in the Diagnosis of Hepatocellular Carcinoma in Middle Eastern Patients. Dig Dis Sci. 2010; 55(12):3568-75.

13. Pivonello C, De Martino MC, Negri M, Cuomo G, Cariati F, Izzo F, et al. The GH-IGF-SST system in hepatocellular carcinoma: biological and molecular pathogenetic mechanisms and therapeutic targets. Infect Agent Cancer. 2014;9:27.

14. Abdel-Wahab R, Shehata S, Hassan MM, Habra MA, Eskandari G, Tinkey PT, et al. Type I insulin-like growth factor as a liver reserve assessment tool in hepatocellular carcinoma. J Hepatocell Carcinoma. 2015;2:131-42.

15. Kaseb A0, Xiao L, Hassan MM, Chae YK, Lee J-S, Vauthey J-N, et al. Development and validation of insulin-like growth factor-1 score to assess hepatic reserve in hepatocellular carcinoma. J Natl Cancer Inst (Internet). 2014;106(5). Available from: http://dx.doi.org/10.1093/ jnci/dju088

16. Alexia C, Fallot G, Lasfer M, Schweizer-Groyer G, Groyer A. An evaluation of the role of insulin-like growth factors (IGF) and of type-I IGF receptor signalling in hepatocarcinogenesis and in the resistance of hepatocarcinoma cells against drug-induced apoptosis. Biochem Pharmacol. 2004;68(6):1003-15.

17. Lei T, Ling X. IGF-1 promotes the growth and metastasis of hepatocellular carcinoma via the inhibition of proteasome-mediated cathepsin B degradation. World J Gastroenterol. 2015;21(35): 10137-49.

18. Baserga R, Peruzzi F, Reiss K. The IGF-1 receptor in cancer biology. International Journal of Cancer. 2003;107(6):873-7.

19. Singh P, Alex JM, Bast F. Insulin receptor (IR) and insulin-like growth factor receptor 1 (IGF-1R) signaling systems: novel treatment strategies for cancer. Med Oncol (Internet). 2013;31(1). Available from: http://dx.doi.org/10.1007/s12032-013-0805-3

20. Wu J, Zhu AX. Targeting insulin-like growth factor axis in hepatocellular carcinoma. J Hematol Oncol. 2011;4:30.

21. Shan J, Shen J, Liu L, Xia F, Xu C, Duan G, et al. Nanog regulates self-renewal of cancer stem cells through the insulin-like growth factor pathway in human hepatocellular carcinoma. Hepatology. 2012;56(3):1004-14.

22. Denduluri SK, Idowu O, Wang Z, Liao Z, Yan Z, Mohammed MK, et al. Insulin-like growth factor (IGF) signaling in tumorigenesis and the development of cancer drug resistance. Genes Dis. 2015;2(1): 13-25.

23. Tovar V, Cornella H, Moeini A, Vidal S, Hoshida Y, Sia D, et al. Tumour initiating cells and IGF/FGF signalling contribute to sorafenib resistance in hepatocellular carcinoma. Gut. 2017;66(3): 530-40.

24. Xu Y, Huang J, Ma L, Shan J, Shen J, Yang Z, et al. MicroRNA-122 confers sorafenib resistance to hepatocellular carcinoma cells by targeting IGF-1R to regulate RAS/RAF/ERK signaling pathways. Cancer Lett. 2016 Feb 28;371(2):171-81.

25. Zhu AX, Ancukiewicz M, Supko JG, Sahani DV, Blaszkowsky LS, Meyerhardt JA, et al. Efficacy, safety, pharmacokinetics, and biomarkers of cediranib monotherapy in advanced hepatocellular carcinoma: a phase II study. Clin Cancer Res. 2013 Mar 15;19(6): 1557-66.

26. Abdel-Wahab R, Shehata S, Hassan MM, Xiao L, Lee J-S, Cheung S, et al. Validation of an IGF-CTP scoring system for assessing hepatic reserve in Egyptian patients with hepatocellular carcinoma. Oncotarget. 2015;6(25):21193-207.

27. Yao Y, Mao W, Dong M, Yang D, Li W, Chen Y. Serum Insulin-Like Growth Factor-1 (IGF-1): a Novel Prognostic Factor for Early Recurrence of Hepatocellular Carcinoma (HCC). Clin Lab. 2017;63(2):261-70.

28. Liu S, Liu Y, Jiang X. Prognostic significance of serum insulin-like growth factor- 1 in patients with hepatocellular carcinoma following transarterial chemoembolization. Exp Ther Med. 2016;11(2):607-12.

29. Vyzantiadis T, Theodoridou S, Giouleme 0 , Harsoulis P, Evgenidis N, 
Vyzantiadis A. Serum concentrations of insulin-like growth factor-I (IGF-I) in patients with liver cirrhosis. Hepatogastroenterology. 2003; 50(51):814-6.

30. Wu Y-L. Clinical significance of serum IGF-I, IGF-II and IGFBP-3 in liver cirrhosis. World J Gastroenterol. 2004;10(18):2740.

31. Colakoglu O, Taskiran B, Colakoglu G, Kizildag S, Ari Ozcan F, Unsal B. Serum insulin like growth factor-1 (IGF-1) and insulin like growth factor binding protein-3 (IGFBP-3) levels in liver cirrhosis. Turk $\mathrm{J}$ Gastroenterol. 2007;18(4):245-9.

32. Aleem E, Elshayeb A, Elhabachi N, Mansour AR, Gowily A, Hela A. Serum IGFBP-3 is a more effective predictor than IGF-1 and IGF-2 for the development of hepatocellular carcinoma in patients with chronic HCV infection. Oncol Lett. 2012;3(3):704-12.

33. Elsammak MY, Amin GM, Khalil GM, Ragab WS, Abaza MM. Possible contribution of serum activin A and IGF-1 in the development of hepatocellular carcinoma in Egyptian patients suffering from combined hepatitis $C$ virus infection and hepatic schistosomiasis. Clin Biochem. 2006;39(6):623-9.

34. Mazziotti G, Sorvillo F, Morisco F, Carbone A, Rotondi M, Stornaiuolo $G$, et al. Serum insulin-like growth factor I evaluation as a useful tool for predicting the risk of developing hepatocellular carcinoma in patients with hepatitis $\mathrm{C}$ virus-related cirrhosis: a prospective study. Cancer. 2002 ;95(12):2539-45.

35. Espelund U, Grønbsk H, Villadsen GE, Simonsen K, Vestergaard PF, Jørgensen JOL, et al. The Circulating IGF System in Hepatocellular Carcinoma: The Impact of Liver Status and Treatment. Growth Horm IGF Res. 2015;25(4):174-81.

36. Wang J, Li Y-C, Deng M, Jiang H-Y, Guo L-H, Zhou W-J, et al. Serum insulin-like growth factor- 1 and its binding protein 3 as prognostic factors for the incidence, progression, and outcome of hepatocellular carcinoma: a systematic review and metaanalysis. Oncotarget. 2017 Oct 6;8(46):81098-108.

37. Rehem RNAMA, El-Shikh WMHM. Serum IGF-1, IGF-2 and IGFBP-3 as parameters in the assessment of liver dysfunction in patients with hepatic cirrhosis and in the diagnosis of hepatocellular carcinoma. Hepatogastroenterology. 2011 May;58(107108):949-54.

38. Harnois DM. Impact of Sirolimus on the Recurrence of Hepatocellular Carcinoma After Liver Transplantation. Yearbook of Gastroenterology. 2010;2010:246.

39. Shetty K, Dash C, Laurin J. Use of adjuvant sorafenib in liver transplant recipients with high-risk hepatocellular carcinoma. J Transplant. 2014 Apr 10;2014:913634.

40. Cholongitas E, Mamou C, Rodríguez-Castro KI, Burra P. Mammalian target of rapamycin inhibitors are associated with lower rates of hepatocellular carcinoma recurrence after liver transplantation: a systematic review. Transpl Int. 2014 Oct:27(10):1039-49.

41. Castroagudín JF, Molina-Pérez E, Ferreiro-Iglesias R, Abdulkader I, Otero-Antón E, Tomé S, et al. Late Recurrence of Hepatocellular Carcinoma after Liver Transplantation: Is an Active Surveillance for Recurrence Needed? Transplant Proc. 2012;44(6):1565-7.

42. Liu D, Chan ACY, Fong DYT, Lo C-M, Khong P-L. Evidence-Based Surveillance Imaging Schedule After Liver Transplantation for Hepatocellular Carcinoma Recurrence. Transplantation. 2017; 101(1):107-11.

43. Bai D-S, Zhang C, Chen P, Jin S-J, Jiang G-Q. The prognostic correlation of AFP level at diagnosis with pathological grade, progression, and survival of patients with hepatocellular carcinoma. Sci Rep. 2017 Oct 9;7(1):12870.

44. Ma W-J, Wang H-Y, Teng L-S. Correlation analysis of preoperative serum alpha-fetoprotein (AFP) level and prognosis of hepatocellular carcinoma (HCC) after hepatectomy. World J Surg Oncol. 2013 Aug 27:11:212.

45. Giard J-M, Mehta N, Dodge JL, Roberts JP, Yao FY. AlphaFetoprotein Slope $>7.5 \mathrm{ng} / \mathrm{mL}$ per Month Predicts Microvascular Invasion and Tumor Recurrence After Liver Transplantation for Hepatocellular Carcinoma. Transplantation. 2018 May;102(5): 816-22.

46. Nicolini D, Mocchegiani F, Palmonella G, Coletta M, Brugia M, Montalti R, et al. Postoperative Insulin-Like Growth Factor 1 Levels Reflect the Graft's Function and Predict Survival after Liver Transplantation. PLoS One. 2015;10(7):e0133153.

47. Salso A, Tisone G, Tariciotti L, Lenci I, Manzia TM, Baiocchi L. Relationship between GH/IGF-1 axis, graft recovery, and early survival in patients undergoing liver transplantation. Biomed Res Int. 2014 Apr 1;2014:240873.

48. Shen L, Xu L, Zhang J, Jiang D. Preoperative Serum Insulin-Like Growth Factor 1 Level as a Prognostic Factor in Patients Undergoing Hepatic Resection for Hepatocellular Carcinoma. J Interferon Cytokine Res. 2018 Apr;38(4):153-60.

49. Houghton LC, Pollak MN, Tao Y, Tu YG, Black A, Bradwin G, et al. Similarity of Serum and Plasma Insulin-like Growth Factor Concentrations. Biomark Cancer. 2015 Jun 8;7:13-7.

50. Renehan AG, Jones J, O'Dwyer ST, Shalet SM. Determination of IGF-I, IGF-II, IGFBP-2, and IGFBP-3 levels in serum and plasma: comparisons using the Bland-Altman method. Growth Horm IGF Res. 2003;13(6):341-6.

51. Berry K, Ioannou GN. Serum alpha-fetoprotein level independently predicts posttransplant survival in patients with hepatocellular carcinoma. Liver Transpl. 2013 Jun;19(6):634-45. 